\title{
McArdle's disease presenting as unexplained dyspnea in a young woman
}

\author{
Nha Voduc MD FRCPC, Katherine A Webb MSc, Christine D'Arsigny MD FRCPC, \\ Ian McBride MSc, Denis E O'Donnell MD FRCPI FRCPC
}

\begin{abstract}
N Voduc, KA Webb, C D’Arsigny, I McBride, DE O’Donnell. McArdle's disease presenting as unexplained dyspnea in a young woman. Can Respir J 2004;11(2):163-167.

McArdle's disease is a rare, inherited deficiency of myophosphorylase, an enzyme required for the utilization of glycogen. Patients with myophosphorylase deficiency classically present with exercise intolerance, leg pain and muscle fatigue. The case of a young woman with exertional dyspnea and leg cramps is described. Exercise testing confirmed the presence of exercise intolerance and demonstrated an accelerated heart rate response, despite the absence of an anaerobic threshold and a respiratory exchange ratio of less than 1.0. Subsequent ischemic forearm testing and muscle biopsy confirmed the diagnosis of myophosphorylase deficiency. Evaluation of lung mechanics with esophageal pressure measurements demonstrated the presence of respiratory muscle weakness and early fatiguability, suggesting that the patient's dyspnea might have been attributable to an increased respiratory effort. Dyspnea is not a classic symptom associated with myophosphorylase deficiency, although subclinical respiratory muscle impairment may be present. No previous studies have evaluated respiratory muscle function during exercise in patients with myophosphorylase deficiency.
\end{abstract}

Key Words: Dyspnea; Exercise; McArdle's disease; Respiratory muscle weakness

M yophosphorylase deficiency is a rare, inherited disorder, first described by McArdle in 1951 (1). McArdle reported a case of exercise limitation and muscle pain in a 30-year-old man, and correctly deduced the presence of a defect in muscle glycogen breakdown, which prevented the muscle utilization of glycogen by skeletal muscle during exercise. The enzyme deficiency responsible was later identified by Schmid and Mahler in 1959 (2). We report the case of a young woman, subsequently diagnosed with McArdle's disease, whose most prominent presenting symptom was severe exertional dyspnea.

\section{CASE PRESENTATION}

A 29-year-old university student was referred for evaluation of shortness of breath. She was a lifelong nonsmoker with no previous history of respiratory illness. Although she had experienced activity-related dyspnea for several years, it had worsened considerably over the previous three years to the point that the symptom was now present on any exertion greater than walking on a level surface. Her dyspnea was accompanied by a perception of chest tightness and an awareness that her heart was
Le syndrome de McArdle se présentant sous forme de dyspnée inexpliquée chez une jeune femme

Le syndrome de McArdle est une rare déficience congénitale en phosphorylase musculaire, une enzyme nécessaire à l'utilisation du glycogène. D'ordinaire, les patients atteints d'une déficience en phosphorylase musculaire présentent une intolérance à l'exercice, des douleurs dans les jambes et une fatigue musculaire. Le cas d'une jeune femme présentant une dyspnée d'effort et des crampes dans les jambes est décrit. Des épreuves d'effort ont confirmé la présence d'intolérance à l'exercice et démontré une réponse d'accélération du rythme cardiaque, malgré l'absence de seuil anaérobique et un quotient respiratoire métabolique inférieur à 1,0 . Une épreuve ischémique subséquente de l'avant-bras et une biopsie musculaire ont confirmé le diagnostic de déficience en phosphorylase musculaire. L'évaluation de la mécanique pulmonaire par des mesures de la pression œesophagienne a démontré la présence d'une faiblesse musculaire respiratoire et d'une fatigabilité précoce, indiquant que la dyspnée de la patiente était peut être attribuable à un accroissement de l'effort respiratoire. La dyspnée n'est pas un symptôme classique à être associé à la déficience en phosphorylase musculaire, bien qu'une atteinte musculaire respiratoire subclinique puisse être présente. Aucune étude antérieure n'a évalué la fonction musculaire respiratoire pendant l'exercice chez les patients atteints d'une déficience en phosphorylase musculaire.

"beating too fast". Initially, she attributed her symptoms to deconditioning from a lack of regular exercise. It was not until she began walking uphill on a regular basis to attend lectures at university that she began to feel that her dyspnea was abnormal. She observed that she would become much more "out of breath" than any of her classmates and could not keep pace with them. There were no precipitating factors for her dyspnea other than exertion, and the dyspnea resolved with rest. There was no history of wheeze, cough, hemoptysis or chest pain.

The patient's only other symptom was muscle stiffness and discomfort, mainly in the thigh muscles during exercise, but she denied any muscle weakness. This symptom began to appear when the patient was approximately eight years of age. It would occur with either sustained lower intensity exercise (walking uphill) or brief periods of high intensity exercise. The leg stiffness would resolve after a brief rest, allowing her to participate in intramural sports in high school. However, in recent years, the patient was not as physically active and, thus, was less frequently bothered by leg discomfort. When questioned about family history, the patient mentioned that her mother 

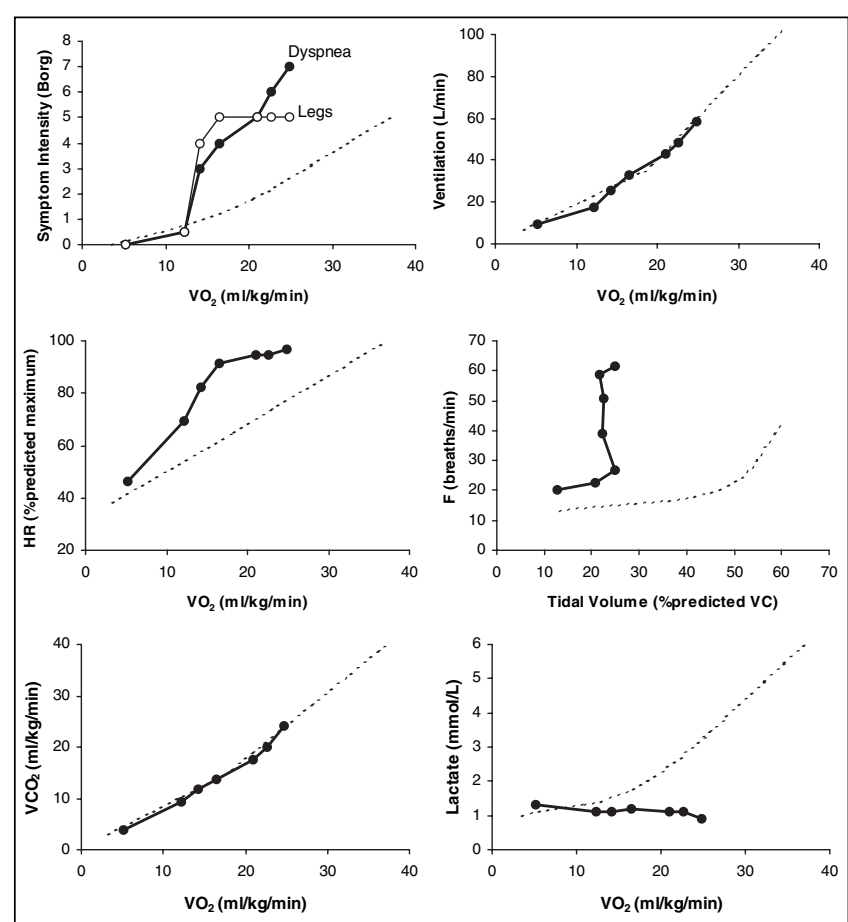

Figure 1) Compared with normal exercise responses (dashed lines), the patient showed greater symptom intensity (dyspnea and leg discomfort), an accelerated heart rate (HR), a rapid and shallow breathing pattern and an absence of increase in blood lactate. F Breathing frequency; $\mathrm{VC}$ Vital capacity; $\mathrm{VCO}_{2}$ Carbon dioxide output; $\mathrm{VO}_{2}$ Oxygen consumption

had also noted leg discomfort with activity during her youth. Apparently, this had not limited her activities to any degree and had not caused her to seek medical attention.

Past medical history was notable only for essential hypertension, which was currently well controlled with irbesartan, an angiotensin receptor blocker.

\section{Examination}

The patient was a healthy looking young woman with a body mass index of $22 \mathrm{~kg} / \mathrm{m}^{2}$. Resting vital signs were normal. A head and neck examination was normal. A cardiovascular examination revealed a normal jugular venous pressure and normal heart sounds, with no murmurs or evidence of pulmonary hypertension. A respiratory examination showed symmetrical chest expansion, with normal auscultatory findings. An abdominal examination was normal. No abdominal paradox was noted. A neurological examination, including muscle strength testing, was normal. No skin rashes, musculoskeletal abnormalities or stigmata of collagen vascular disease were noted.

\section{Investigations}

The patient was first referred to a cardiologist for evaluation of her dyspnea in 1999; a subsequent electrocardiogram and echocardiogram were normal, and no significant cardiac dysfunction was identified. Complete blood count, urea, electrolytes, creatinine kinase and thyroid function test results were normal. She was later evaluated by a respirologist, who arranged for chest radiographs, pulmonary function tests and an incremental cycle exercise test. The chest films and pulmonary function tests (spirometry, lung volumes and diffusion capacity) were normal. The exercise test was limited by equipment problems. The patient stopped exercising after only $3 \mathrm{~min}$ at a low peak work rate of $90 \mathrm{~W}$ (63\% of predicted maximum). Her heart rate was 78 beats/min at baseline, rising steeply to 184 beats/min at the end of exercise. Her blood pressure rise was normal. Arterial oxygen saturation remained between $98 \%$ to $99 \%$ throughout the test. Arterial blood gases drawn at the end of exercise revealed a mild respiratory alkalosis $(\mathrm{pH}$ 7.39, partial pressure of carbon dioxide $30 \mathrm{mmHg}$, bicarbonate $23 \mathrm{mEq} / \mathrm{L}$, partial pressure of oxygen $119 \mathrm{mmHg}$ ).

The patient was then referred to Queen's University (Kingston, Ontario) for further evaluation of her unexplained dyspnea and exercise intolerance. All pulmonary function and exercise testing was performed by an experienced research assistant. Repeat pulmonary function tests again showed normal spirometry, lung volumes and diffusion capacity. However, maximal inspiratory flow rates appeared lower than normal. The maximal inspiratory occlusion pressure measured at functional residual capacity was $-61 \mathrm{~cm} \mathrm{H}_{2} \mathrm{O}$ (69\% predicted [3]), and the maximal expiratory pressure measured at total lung capacity was $89 \mathrm{~cm} \mathrm{H}_{2} \mathrm{O}$ (58\% predicted [4]). Because the patient reported that most of her difficulty occurred during walking, incremental cardiopulmonary exercise testing was repeated using a treadmill. A stepwise protocol using $2 \mathrm{~min}$ increments of $0.8 \mathrm{~km} / \mathrm{h}$ was used. During exercise, cardiopulmonary parameters were collected in a breath-by-breath fashion, the modified Borg scale (5) was used to rate the intensity of breathing and leg discomfort and inspiratory capacity maneouvres were performed to assess operating lung volumes. With this gradual protocol, the patient reached a low peak, symptom-limited oxygen consumption $\left(\mathrm{VO}_{2}\right)$ of $24.8 \mathrm{~mL} / \mathrm{kg} / \mathrm{min}$ or $67 \%$ of predicted normal. Very severe dyspnea (Borg scale score 7) was reported as the main limiting symptom, although severe leg discomfort was present as well (Borg scale score 5) (Figure 1). An accelerated cardiac response was again noted, with the patient's heart rate quickly reaching the age-predicted maximum (184 beats/min, 97\% predicted). Peak ventilation was only $48 \%$ of the estimated maximal ventilatory capacity $(35 \times$ forced expiratory volume in $1 \mathrm{~s})$. Breathing during exercise was relatively rapid and shallow, with the tidal volume remaining less than $1.0 \mathrm{~L}$ (27\% of the vital capacity) and the respiratory rate reaching 61 breaths/min.

Evaluation of exercise flow-volume loops revealed no evidence of expiratory flow limitation and an adequate volume reserve at peak exercise (inspiratory reserve volume was $0.8 \mathrm{~L}$ ). At peak exercise, tidal inspiratory flows approached or met the maximal inspiratory flows measured at isovolume. Esophageal pressure $\left(\mathrm{P}_{\mathrm{es}}\right)$ measurements were performed before and during exercise testing. Maximal sniff $\mathrm{P}_{\mathrm{es}}$ at rest was reduced at $-46 \mathrm{~cm} \mathrm{H} \mathrm{H}_{2} \mathrm{O}$; a value of below $-60 \mathrm{~cm} \mathrm{H}_{2} \mathrm{O}$ is likely to be associated with significant inspiratory muscle weakness (6). During exercise, there was a further reduction in the magnitude of the maximal inspiratory $\mathrm{P}_{\text {es }}\left(-16.7 \mathrm{~cm} \mathrm{H}_{2} \mathrm{O}\right)$. Tidal inspiratory $\mathrm{P}_{\mathrm{es}}$ comprised an abnormally high proportion $(73 \%)$ of the maximal inspiratory $\mathrm{P}_{\text {es }}$ generated during coinciding maximal inspiratory capacity maneouvres. Because detailed normative data are not available for measurements of respiratory mechanics 
TABLE 1

Measurements of respiratory mechanics at the peak of symptom-limited exercise in the patient compared with a control subject at a similar level of exercise $(6.4 \mathrm{~km} / \mathrm{h}$, $3.5 \%$ grade)

\begin{tabular}{lcc}
\hline & Case subject & Control subject $^{*}$ \\
\hline Dyspnea intensity (Borg scale score) & 7 (very severe) & 3 (moderate) \\
Oxygen consumption $(\mathrm{L} / \mathrm{min})$ & 1.47 & 1.48 \\
Ventilation $(\mathrm{L} / \mathrm{min})$ & 58.1 & 32.2 \\
Tidal volume $(\mathrm{L})$ & 0.95 & 1.37 \\
Tidal volume $(\%$ vital capacity) & 27 & 29 \\
Breathing frequency (breaths/min) & 61 & 24 \\
Peak inspiratory $\mathrm{P}_{\mathrm{es}}\left(\mathrm{cm} \mathrm{H}_{2} \mathrm{O}\right)$ & -12.2 & -8.4 \\
Dynamic $\mathrm{PI}_{\text {max }}\left(\mathrm{cm} \mathrm{H}_{2} \mathrm{O}\right)$ & -16.7 & -38.6 \\
Inspiratory $\mathrm{P}_{\mathrm{es}} / \mathrm{PI}_{\max }(\%)$ & 73 & 22 \\
\hline
\end{tabular}

*Values for a healthy control subject matched for age, sex and body size. $P_{e s}$ Esophageal pressure; $P I_{\text {max }}$ Dynamic maximal inspiratory pressures measured during maximal inspiratory capacity maneouvres performed immediately after the reported peak/control measurements

during exercise, the patient's responses were compared with those of a healthy control subject matched for age, sex and body size (Table 1, Figures 2 and 3 ).

The respiratory exchange ratio (carbon dioxide output $/ \mathrm{VO}_{2}$ ) remained at less than 1.0 throughout exercise, with no anaerobic threshold identified by the V-slope method. Venous blood lactate levels were low and did not increase during exercise. Ammonia levels increased normally. The low respiratory exchange ratio and lack of rise in lactate, despite attainment of maximum predicted heart rate and the presence of intolerable exertional symptoms, collectively suggested a metabolic myopathy as the cause of her exercise intolerance.

Consent was therefore obtained for an ischemic forearm test. Baseline bloodwork drawn before the forearm test revealed a creatine kinase level of $2038 \mathrm{U} / \mathrm{L}$; myoglobinuria was absent. During the forearm test, a blood pressure cuff was inflated $10 \mathrm{mmHg}$ above systolic pressure over the patient's arm. The patient was then instructed to perform repeated handgrips with a blood pressure bulb, at a rate of 1 handgrip/s. The test was ended after approximately $1 \mathrm{~min}$, when the patient developed a painful contracture of her hand. A fivefold rise in ammonia from venous return blood was noted at the end of the test, confirming that an adequate effort was made. Despite this, there was no rise in serum lactate levels, indicating a defect in muscle glycogenolysis.

The patient was subsequently referred for a quadriceps muscle biopsy. Periodic acid Schiff staining revealed the presence of abnormal subsarcolemmal glycogen deposits in muscle tissue, a typical finding in glycogen metabolism disorders. Staining for myophosphorylase activity was performed and was clearly negative, confirming the diagnosis of myophosphorylase deficiency.

\section{DISCUSSION}

To our knowledge, progressive, severe exertional dyspnea has not previously been reported as a presenting symptom of McArdle's disease. Detailed cardiopulmonary exercise testing and ventilatory muscle assessment provided new insights into the possible cause of this patient's respiratory symptoms.

Cardiopulmonary exercise testing confirmed that intolerable exertional dyspnea was the main exercise-limiting symptom in this patient. Ventilation increased appropriately in

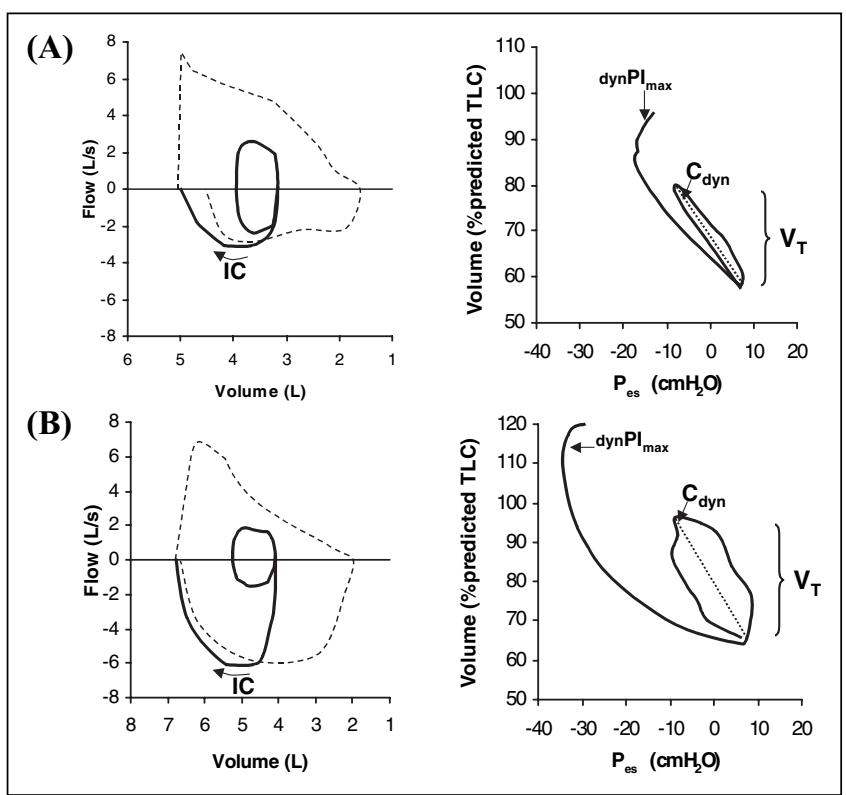

Figure 2) Tidal and maximal flow-volume and pressure-volume curves are shown at the peak of exercise (A) and at a similar level of exercise for a matched control subject (B). Note the reduction in maximal inspiratory flow and the nearness of tidal inspiratory flows to maximum (Left panel). Similarly, tidal inspiratory esophageal pressures $\left(P_{0}\right)$ approach the maximal inspiratory pressure determined dynamically $\left(\right.$ dynPI ${ }_{\max }$ ) by a maximal inspiratory capacity (IC) maneouvre (Right panel). $\mathrm{C}_{d y n}$ Dynamic compliance; TLC Total lung capacity; $V_{T}$ Tidal volume

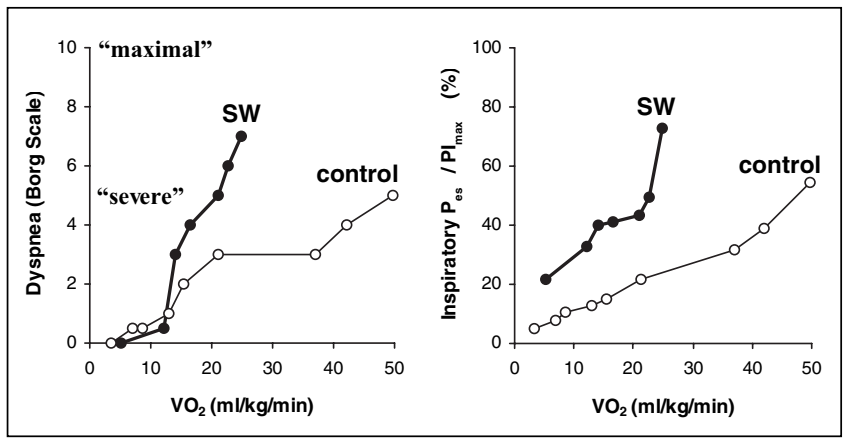

Figure 3) Plots of dyspnea intensity (Borg scale) and inspiratory 'effort' (esophageal pressure $\left[\mathrm{P}_{e s}\right] /$ maximal inspiratory pressure $\left[\mathrm{PI}_{\max }\right]$ ) are shown against oxygen consumption $\left(\mathrm{VO}_{2}\right)$ during exercise for the patient (SW) and a matched control subject

response to $\mathrm{VO}_{2}$ with apparent ventilatory reserve at the end of exercise. This finding, coupled with the fact that the predicted maximal heart rate was reached at the end of exercise, may lead to the (erroneous) conclusion that exercise was predominantly limited by cardiac factors. However, closer scrutiny reveal that serious ventilatory constraints existed in this patient during exercise. Breathing pattern responses were abnormal: the peak tidal volume was only $27 \%$ of vital capacity (normally $50 \%$ to $60 \%$ ), and there was inordinate tachypnea (61 breaths/min). In the absence of evidence of any mechanical restriction of ventilation (ie, lung or chest wall restriction, or expiratory flow limitation or dynamic lung hyperinflation), the likely cause of this rapid, shallow breathing pattern is inspiratory muscle weakness or behavioural factors (eg, anxiety). The 
presence of an adequate inspiratory reserve volume at peak exercise favours inspiratory muscle weakness rather than mechanical restriction as a cause of the reduced tidal volume. Corroborating evidence for inspiratory muscle weakness also included low resting sniff $\mathrm{P}_{\mathrm{es}}$, substantial further reductions in sniff $\mathrm{P}_{\mathrm{es}}$ during exercise and low maximum inspiratory flows.

It is interesting to note that measurements of respiratory muscle function at rest (maximum inspiratory and expiratory occlusion pressures) do not allow one to appreciate the full extent of the present patient's respiratory muscle weakness. Although her results were below average, they were not clearly outside the wide range of normal values for these measurements. Conventional predictors of maximal ventilatory capacity (forced expiratory volume in $1 \mathrm{~s} \times 35$ ) also greatly overestimated the patient's true ventilatory capacity. In contrast, flow-volume loop analysis and measurements of respiratory muscle function obtained during exercise suggested that muscle fatigue might have been responsible for exercise limitation. At peak exercise, inspiratory flows during tidal respiration approached the maximal flow-volume curve, suggesting that further increases in inspiratory flow were not possible (Figure 2). Furthermore, the ratio of tidal inspiratory pressure to maximum inspiratory pressure $\left(\mathrm{P}_{\mathrm{es}} /\right.$ maximal inspiratory pressure) was much greater than normal and was in the range in which fatigue would be expected. The progressive reduction of inspiratory capacity (in the absence of expiratory flow limitation) and peak inspiratory pressures throughout exercise, together with a high tensiontime index (greater than 0.15), are also indirect indicators of the presence of fatigue. It is likely that the patient's myophosphorylase deficiency is responsible for the development of inspiratory muscle fatigue. The inability of her respiratory muscles to utilize glycogen limits their ability to meet the increased ventilatory demands of exercise.

The cause of the patient's severe dyspnea remains conjectural. Despite significant ventilatory dysfunction and a rapid shallow pattern that could compromise carbon dioxide elimination, there was no evidence to suggest that dyspnea was related to acute respiratory insufficiency at the end of exercise. On the contrary, mild alveolar hyperventilation was present. In the presence of inspiratory muscle weakness or fatigue, greater central motor command output is required for any given force generation by the muscle (7-9). It is believed that sensory information regarding this increased motor output is conveyed to the cortex, via central corollary discharge, where it is perceived as an increased breathing effort $(7,8)$. In the absence of other dyspneogenic stimuli, such as mechanical factors, hypoxemia or hypercapnia, heightened respiratory effort is likely to be one component of this patient's dyspnea (9). Similarly, muscle weakness and fatigue of the exercising leg muscles, as well as the attendant increased motor command output, may form the basis for her perception of severe leg discomfort (10).

Porte el al (11) were the first to describe the results of cardiopulmonary exercise testing in a patient with McArdle's disease. An accelerated heart rate response is typically observed, but the reasons for this remain elusive. The fact that our patient reached her heart rate ceiling early in exercise does not necessarily mean that cardiac output was reduced or that cardiac limitation to exercise was present. Extensive cardiac investigations were, in fact, normal. Heart rate responses to exercise depend on the balance between the prevailing sympathetic and parasympathic influences on the sinus node $(12,13)$. Central command contributes importantly to increased sympathetic activity and increased heart rate during exercise $(14,15)$. However, stimulation of free nerve endings in the exercising muscles by metabolite accumulation (ie, potassium, phosphate, lactate, carbon dioxide) is believed to be the most powerful stimulus for increased sympathetic drive and cardioacceleration. Recent studies have shown that acid accumulation in the muscle is not obligatory to this metaboreflex activation - sympathetic neural activity increases normally with high intensity forearm exercise in patients with McArdle's disease (16). Severe skeletal muscle deconditioning as a result of inactivity, respiratory distress and leg pain collectively increase sympathetic activity and likely contributed to this patient's increased heart rate.

\section{Management}

There is no definitive treatment for McArdle's disease. High protein diets and vitamin $\mathrm{B}_{6}$ supplementation have been reported to be beneficial $(17,18)$, although neither of these treatments are universally accepted.

Regular physical activity should be encouraged in patients with myophosphorylase deficiency because many reduce their daily activity to avoid muscle pain. However, patients must be cautioned not to overexert to the point that muscle pain develops. Patients with myophosphorylase deficiency are at risk for rhabdomyolysis after strenuous exertion. The release of myoglobin can be associated with kidney damage, with approximately $50 \%$ of patients eventually having some evidence of renal dysfunction (11). Patients must be counselled to avoid dehydration and seek medical attention if their urine darkens (suggesting the presence of myoglobinuria). In addition to renal impairment, some patients also develop progressive, fixed muscle weakness over time due to repeated muscle damage (and loss of skeletal muscle fibres) from episodes of rhabdomyolysis (19).

No myoglobinuria was detected in our patient, and she had neither evidence of renal impairment nor overt peripheral muscle weakness. Genetic counselling for her family members was arranged.

\section{CONCLUSIONS}

Previous papers that examined the ventilatory response of patients with McArdle's disease did not include an analysis of respiratory pressures and mechanics. This makes it impossible to determine the prevalence of respiratory muscle impairment in this condition. Therefore, it is uncertain whether this case represents a rare manifestation or a common finding in patients with McArdle's disease. Regardless, the present case demonstrates that serious inspiratory muscle dysfunction can certainly occur and it may present clinically as severe, progressive exertional dyspnea.

\section{REFERENCES}

1. McArdle B. Myopathy due to a defect in muscle glycogen breakdown. Clin Sci Lond 1951;10:13-33.

2. Schmid R, Mahler D. Chronic progressive myopathy with myoglobinuria: Demonstration of a glycolytic defect in muscle. J Clin Invest 1959;38:2044-58.

3. Hamilton AL, Killian KJ, Summers E, Jones NL. Muscle strength, symptom intensity, and exercise capacity in patients with cardiorespiratory disorders. Am J Respir Crit Care Med 1995;152:2021-31. 
4. Black LF, Hyatt RE. Maximal respiratory pressures: Normal values, and relationship to age and sex. Am Rev Respir Dis 1969;99:696-702.

5. Borg GAV. Psychophysical basis of perceived exertion.

Med Sci Sports Exerc 1982;14:377-81.

6. American Thoracic Society/European Respiratory Society. ATS/ERS Statement on respiratory muscle testing. Am J Respir Crit Care Med 2002;166:518-624.

7. Chen Z, Eldridge FL, Wagner PG. Respiratory-associated rhythmic firing of mid-brain neurons in cats: Relation to level of respiratory drive. J Physiol (Lond) 1991;437:305-25.

8. Chen Z, Eldridge FL, Wagner PG. Respiratory-associated thalamic activity is related to level of respiratory drive. Respir Physiol 1992;90:99-113.

9. Leblanc P, Bowie DM, Summers E, Jones NL, Killian KJ. Breathlessness and exercise in patients with cardio-respiratory disease. Am Rev Respir Dis 1986;133:21-5.

10. Gandevia SC. The perception of motor commands on effort during muscular paralysis. Brain 1982;105:151-95.

11. Porte D, Crawford DW, Jennings DB, Aber C, McIlroy MB. Cardiovascular and metabolic responses to exercise in a patient with McArdle's syndrome. N Engl J Med 1966;275:406-12.

12. Victor RG, Bertocci LA, Pryor SL, Nunnally RL. Sympathetic nerve discharge is coupled to muscle cell $\mathrm{pH}$ during exercise in humans. J Clin Invest 1988;82:1301-5.
13. Haouzi P, Hill JM, Lewis BK, Kaufman MP. Responses of group III and IV muscle afferents to distension of the peripheral vascular bed. J Appl Physiol 1999;87:545-53.

14. Waldrop TG, Eldridge FL, Iwamoto GA, Mitchell JH. Central neural control of respiration and circulation during exercise. In: Rowell LB, Shepherd JT, eds. Handbook of Physiology, Section 12. Exercise: Regulation and Integration of Multiple Systems. New York: Oxford University Press for the American Physiological Society, 1996:333-80.

15. Querry RG, Smith SA, Stromstad M, Ide K, Raven PB, Secher NH. Neural blockade during exercise augments central command's contribution to carotid baroreflex resetting. Am J Physiol Heart Circ Physiol 2001;280:H1635-44.

16. Vissing J, Vissing SF, MacLean DA, Saltin B, Quistorff B, Haller RG. Sympathetic activation in exercise is no dependent on muscle acidosis: Direct evidence from studies in metabolic myopathies. J Clin Invest 1998;101:1654-60.

17. Phoenix J, Hopkins P, Bartram C, Beynon RJ, Quinlivan RCM, Edwards RHT. Effect of vitamin B6 supplementation in McArdle's disease: A strategic case study. Neuromuscul Disord 1998;8:210-2.

18. Slonim AE, Goans PJ. Myopathy in McArdle's syndrome: Improvement with a high-protein diet. N Engl J Med 1985;312:355-9.

19. Dimauro S, Bresolin N. Phosphorylase deficiency. In: Engel A, Banker B, eds. Myology. New York: McGraw-Hill, 1986:1585. 


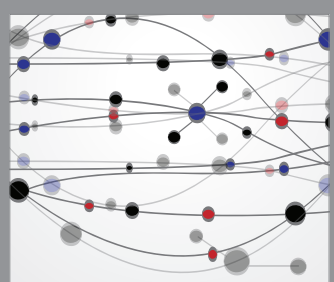

The Scientific World Journal
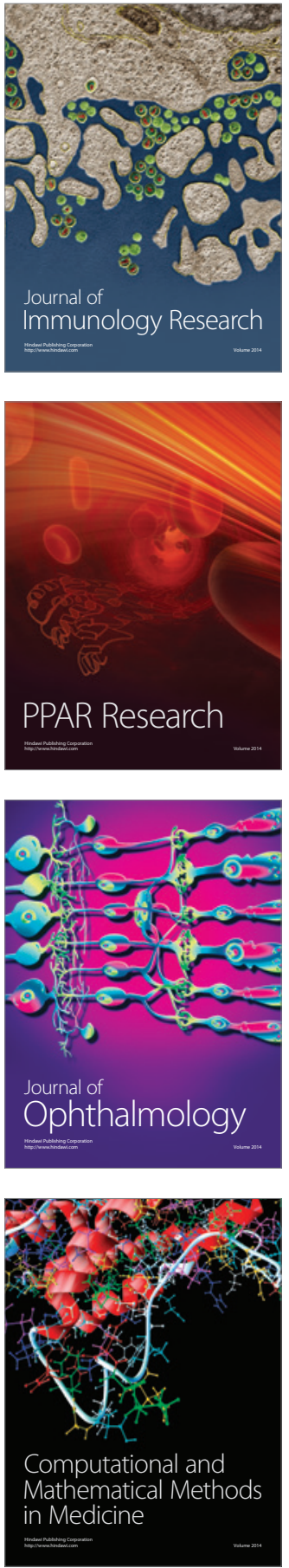

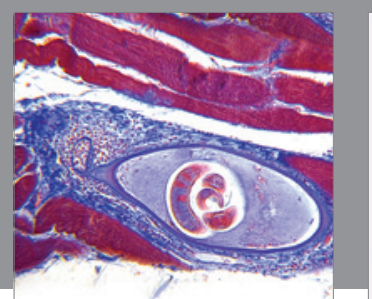

Gastroenterology Research and Practice

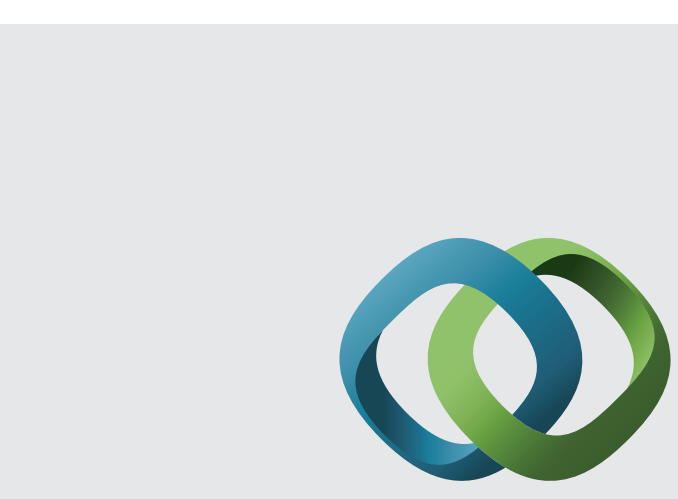

\section{Hindawi}

Submit your manuscripts at

http://www.hindawi.com
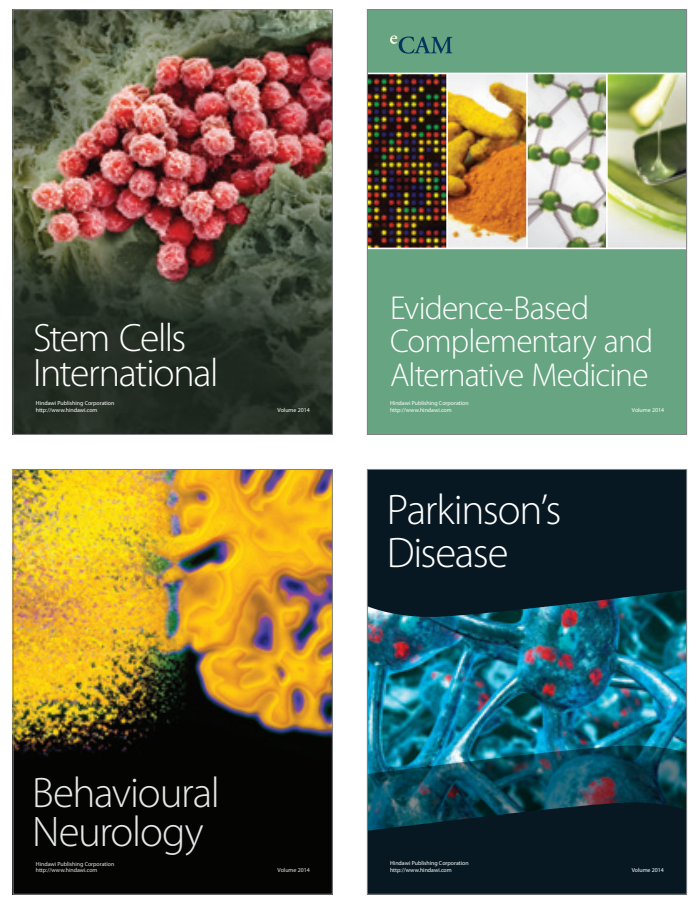
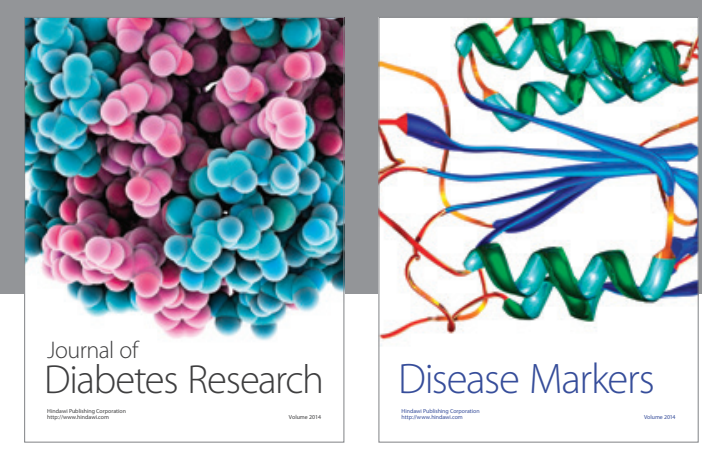

Disease Markers
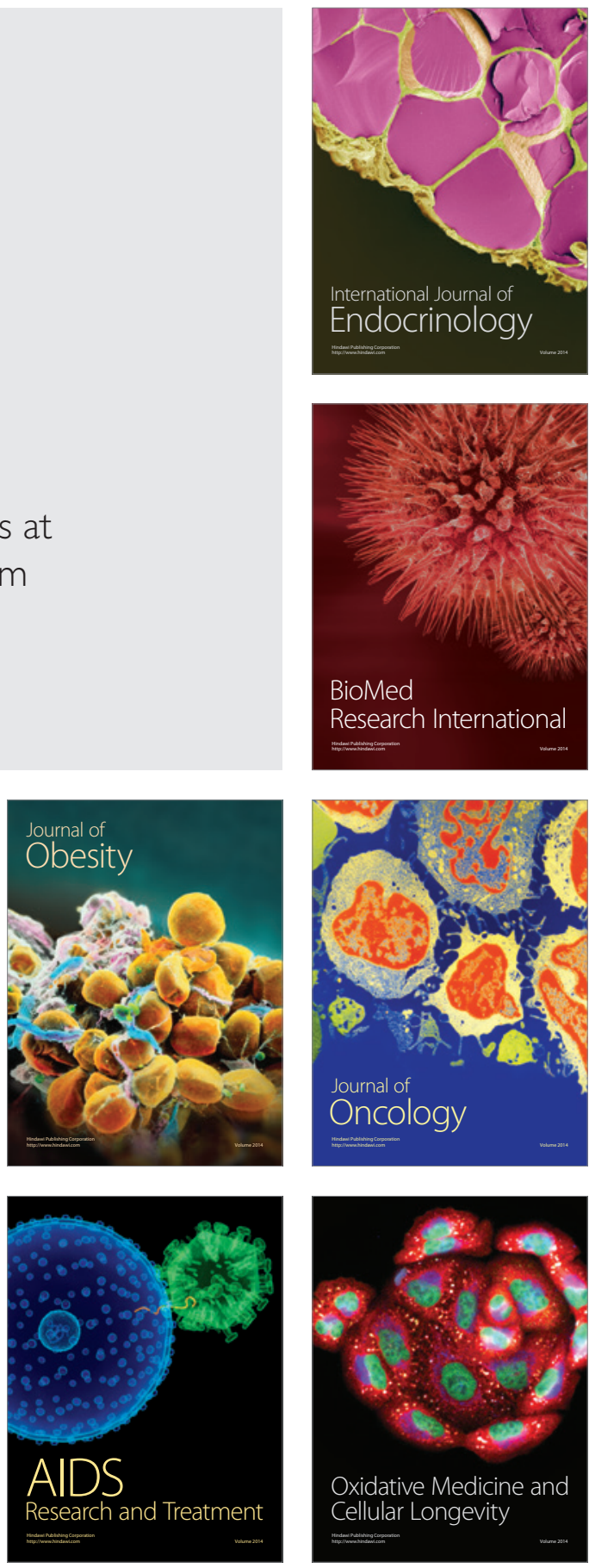